\title{
Perceptions of Mothers regarding the Importance of Breastfeeding
}

\author{
Bruna Fernandes Boaventura ${ }^{1}$, Julia Ramos de Campos Silva ${ }^{1}$, \\ Oriane da Silva Pimenta ${ }^{1}$, Rubens José Bombardi Neto ${ }^{1}$, \\ Bruno dos Reis Santos ${ }^{1}$, Alan Wilson Fortunato ${ }^{1}$, \\ Matheus Martins de Freitas ${ }^{1}$, Antônio Carlos Tonelli Gusson ${ }^{2}$
}

\author{
${ }^{1}$ Undergraduate Student, São José Rio Preto School of Medicine (FAMERP), Brazil \\ ${ }^{2}$ Department of Pediatrics, São José Rio Preto School of Medicine (FAMERP), Brazil
}

\begin{abstract}
Objective: To identify the perceptions of mothers regarding the importance of breastfeeding. A crosssectional study was conducted with a sample of 385 mothers recruited from three locations: a general hospital $(n=73)$, children's hospital $(n=227)$ and the Pro-Infancy Clinic $(n=85)$. Data were collected using a semi-structured questionnaire on breastfeeding. Data analysis considered absolute and relative frequencies. Among the 385 mothers, 9.4\% were not counseled regarding the properties and benefits of breast milk. The desire to breastfeed during pregnancy changed in $24.7 \%$ mothers after the child was born. The main difficulties during breastfeeding were "nipple pain and injury" (64.7\%) and "altered sleep pattern" (63.6\%). A total of $32.2 \%$ participants had difficulty reconciling breastfeeding and work; $65.5 \%$ of mothers introduced artificial milk, juices, teas, water, and cow's milk before six months of age; and $72.5 \%$ used pacifier/bottle feeding before six months of age. Difficulties during breastfeeding and the justifications of mothers who do not breastfeed show that simple measures can increase adherence to and the maintenance of breastfeeding. Maternity leave among working women is a favorable measure for the maintenance of exclusive breastfeeding. The assurance of exclusive breastfeeding for a longer time could probably reduce the use of devices such as a pacifier/bottle-feeding and lead to the later introduction of complementary foods, which are the main causes of the discontinuation of breastfeeding.
\end{abstract}

Keywords: Breastfeeding, Weaning, Parental Leave, Child Health

\begin{abstract}
Introduction
The entrance of women in the job market and the increase in the manufacturing of food products with the advent of the Industrial Revolution in the second half of the $18^{\text {th }}$ century constituted the first challenges to the practice of breastfeeding, ${ }^{1}$ which continue to the present day. This is a worrisome situation in terms of child health, as the nutritional and immunological properties of breastmilk protect newborns from infection, diarrhea and respiratory disease, contributing to favorable development, the strengthening of the mother-infant bond and a reduction in the child mortality rate. ${ }^{2-4}$
\end{abstract}

A study published in 2017 reports that $40 \%$ of infants in 194 countries are breastfed exclusively until six months of age. ${ }^{5}$ Considering the significant potential of breastfeeding for the reduction in the mortality rate, the World Health Organization (WHO) recommends the practice of exclusive breastfeeding for at least six months and breastfeeding with additional foods up to two years or more. ${ }^{6}$ Brazil has been trying to meet global goals, but the situation in the country continues to be far from what is considered ideal for children. Data published by the Health Ministry in 2009 show that only $48 \%$ of infants less than two months of age were on exclusive breastfeeding and $14 \%$ were already being fed semisolid foods, with an increase in this percentage in subsequent months. ${ }^{7}$

To understand this situation, we must look as the causes of premature weaning. The first difficulty is the fact that each mother attributes subjective importance to the practice of breastfeeding, which is influenced by her emotional, social, cultural and economic characteristics. ${ }^{8}$ One of the emotional changes that exert an influence on premature weaning is the break from the expectation of the experience of breastfeeding ${ }^{9}$ as well as from parental expectations regarding the infant imagined during pregnancy. ${ }^{10}$ Factors such as anxiety, depression, lowered selfesteem and a negative paternal influence also hinder breastfeeding. Winnicott ${ }^{11}$ found that a frequent perturbation in mothers during breastfeeding was the sensation of being "sucked dry and enslaved" - being 
dispossessed of themselves. Such unconscious conflicts can lead to difficulties, generating ambiguous and contradictory feelings, as many associate between being a "good mother" with being a good producer of breast milk, which can lead to suffering. 10

Moreover, inadequate latching/sucking can cause injury, pain and discomfort, which can lead mothers to discontinue breastfeeding if the problem is not corrected. $^{12,13}$ Another considerable challenge is the reconciliation between work and breastfeeding, ${ }^{14,15}$ which is often associated with the need to generate income for the subsistence of the family.

Health professionals should not limit their actions to the sharing of information on the benefits of breast milk to the health of the infant. There should also be understanding and counseling that considers a mother's decisions regarding breastfeeding. Psychological support is needed so that the guilt of not breastfeeding does not lead to conflicts in the mother-infant relationship. Thus, an interdisciplinary approach involving an understanding of the social context is important to the promotion, protection and support of breastfeeding, prioritizing the child, mother and family with regards to the practice. ${ }^{16}$

The aim of the present study was to identify the perceptions of mothers regarding the importance of breastfeeding.

\section{Methods}

A descriptive cross-sectional study was conducted with a convenience sample of 385 mothers (lactating or not), independently of race, age group and socioeconomic status. The mothers were recruited between August and December 2018 from three locations in the city of São José do Rio Preto, Brazil: a children's hospital, the clinic of a general hospital and the Pro-Infancy Clinic.

This study received approval from the Human Research Ethics Committee of the São José do Rio Preto School of Medicine (certificate number: 88818318.4.0000.5415). All participants received clarifications regarding the objectives and importance of the study and signed a statement of informed consent. In cases of mothers less than 18 years of age, the consent form was signed by a legal guardian.

Data collection involved the administration of a semistructured questionnaire addressing demographic (mother's age, number of children), socioeconomic (profession, difficulty reconciling work, level of schooling, marital status) and clinical (prenatal care, counseling during pregnancy and the postnatal period, duration of breastfeeding, difficulties, introduction of other foods) characteristics. To identify difficulties encountered during breastfeeding, the mothers were asked to classify 12 factors (fear of breastfeeding, "weak milk", feeling "sucked dry/enslaved", nipple pain or injuries, depression/stress/anxiety, lowered self-esteem, negative interference of partner/child's father, interference of family members/acquaintances, loss of independence, change in sleep pattern, change in eating pattern, reconciliation with work) on a scale of 0 to 5 , depending on the occurrence and degree of difficulty: 0 = no difficulty; 1 (minimum difficulty) to 5 (maximum difficulty).

The database was organized in Microsoft Excel® (Microsoft Corp., USA). Absolute and relative frequencies were calculated for the description of the variables of interest.

\section{Results and Discussion}

The 385 participants answered the questionnaire at the children's hospital $(n=227)$, clinic of the general hospital $(n=73)$ and Pro-Infancy Clinic $(n=85)$. Table 1 displays the distribution of the variables of interest.

\section{Influence of health professionals}

Thirty-six $(9.4 \%)$ of the 385 participants reported not having received counseling on the properties and benefits of breast milk. Only three of these women (8.3\%) did not undergo prenatal care during pregnancy. This indicates that the other 33 had adequate prenatal follow-up but were not counseled by health professionals regarding the properties of breast milk and its importance to the healthy development of the infant.

Table 1. Demographic and socioeconomic characteristics of participants $(\mathrm{n}=385)$. São José do Rio Preto, 2018.

\begin{tabular}{|c|c|c|c|}
\hline Variables & & $\mathrm{n}$ & $\%$ \\
\hline \multirow{5}{*}{ Age group (years) } & $\leq 18$ & 4 & 1.0 \\
\hline & $19-28$ & 89 & 23.1 \\
\hline & $29-38$ & 182 & 47.3 \\
\hline & $39-48$ & 77 & 20.0 \\
\hline & 49 or more & 33 & 8.6 \\
\hline \multirow[t]{2}{*}{ Number of children } & primiparous & 141 & 36.6 \\
\hline & multiparous & 244 & 63.4 \\
\hline \multirow{6}{*}{ Profession } & housekeeper/homemaker & 108 & 28.1 \\
\hline & unemployed & 18 & 4.7 \\
\hline & self-employed & 125 & 32.5 \\
\hline & retired & 5 & 1.3 \\
\hline & student & 6 & 1.5 \\
\hline & other & 117 & 30.4 \\
\hline
\end{tabular}




\begin{tabular}{|c|c|c|c|}
\hline & did not answer & 6 & 1.5 \\
\hline \multirow{4}{*}{ Level of schooling } & $\leq$ complete primary school & 51 & 13.3 \\
\hline & complete high school & 241 & 62.6 \\
\hline & complete university & 89 & 23.1 \\
\hline & did not answer & 4 & 1.00 \\
\hline \multirow{4}{*}{ Marital status } & single & 81 & 21.0 \\
\hline & married & 259 & 67.3 \\
\hline & divorced & 35 & 9.1 \\
\hline & widowed & 10 & 2.6 \\
\hline
\end{tabular}

These findings are worrisome, as the encouragement of exclusive breastfeeding is one of the major health actions. Health professionals exert considerable influence on the knowledge, attitudes and behaviors of mothers with regards to breastfeeding, particularly during the prenatal and immediate postnatal periods. Moreover, $105(27.8 \%)$ and $45(11.7 \%)$ reported not receiving such counseling from obstetricians or pediatricians, respectively, and $152(39.5 \%)$ reported not receiving counseling from other health professionals. Among those who received counseling, there was a predominance of professionals in the field of nursing $\quad(n=179)$, followed by speech therapy $(n=27)$ and nutrition $(n=13)$.

Despite the importance of the advice of these health professionals to the establishment and maintenance of breastfeeding, when such counseling is given, it often comes from a presupposition that breastfeeding is natural and a mother's duty. This reduces the mother to a nourishing function, denying her the condition of being human in the process. ${ }^{17}$

\section{Desire to breastfeed}

Ninety-five women $(24.7 \%)$ reported a change in the desire to breastfeed from pregnancy to the postnatal period. Among these women, $63(66.3 \%)$ had the desire during the pregnancy but no longer had the desire after the child was born. In contrast, 32 (33.7\%) did not have the desire during pregnancy but had the desire after the child was born. For the other $290(75.3 \%)$ of mothers, no change occurred in the desire to breastfeed. Among these women, 277 $(95.5 \%)$ had the desire both during pregnancy and after the child was born and the other $13(4.5 \%)$ did not have the desire either during pregnancy or after the child was born, three of whom did not breastfeed.

It is not enough for a woman to want to breastfeed and understand the advantages and the recommended duration for this practice to be effectively established and maintained. It is fundamental for mothers also to be in a favorable environment.

\section{Difficulties during breastfeeding}

Regarding the difficulties encountered during breastfeeding and respective degrees according to the 385 mothers (Table 2), the main complaints were a "change in sleep pattern" (63.6\% had some degree of difficulty) and "nipple pain and injury" (64.7\% had some degree of difficulty). "Negative interference of the partner/child's father" was the most common difficulty (94\%). Moreover, "fear of breastfeeding" was the third most common reason among the women who did not breastfeed their children.

Table 2. Difficulties encountered during breastfeeding and respective degrees $(\mathrm{n}=385)$. São José do Rio Preto, 2018

\begin{tabular}{lcccccc}
\hline Difficulty & Degree: & 0 & 1 & 2 & 3 & 4 \\
\hline fear of breastfeeding & 284 & 11 & 10 & 14 & 11 & 19 \\
"weak" milk & 222 & 10 & 17 & 32 & 14 & 54 \\
feeling "sucked dry"/"enslaved" & 288 & 9 & 17 & 10 & 18 & 43 \\
nipple pain or injury & 136 & 23 & 7 & 6 & 23 & 130 \\
depression, stress or anxiety & 274 & 17 & 11 & 26 & 18 & 39 \\
lowered self-esteem & 282 & 11 & 21 & 23 & 14 & 34 \\
interference of family/acquaintances & 265 & 12 & 16 & 28 & 10 & 54 \\
negative interference of partner/child's father & 362 & 2 & 3 & 4 & 0 & 14 \\
loss of independence & 277 & 9 & 27 & 20 & 10 & 42 \\
change in sleep pattern & 140 & 11 & 23 & 53 & 37 & 120 \\
change in eating pattern & 208 & 14 & 23 & 46 & 31 & 63 \\
reconciliation with work & 259 & 11 & 11 & 19 & 9 & 76
\end{tabular}


Breastfeeding and work

Among the 385 participants, 108 (28.1\%) were housekeepers (homemakers and maids in the homes of others). A large number of women who worked were unregistered (without signed working papers) (n $=235 ; 61 \%$ ).

Regarding the difficulty reconciling breastfeeding and work, $261(67.8 \%)$ reported not having problems, $93(35.6 \%)$ of whom were registered workers, 32 $(12.3 \%)$ were unregistered workers and $136(52.1 \%)$ did not work at the time. Among those with formal work during breastfeeding, only $15(16.1 \%)$ stated that the reconciliation was only possible due to maternity leave. Although this number shows the employment status of the women (the majority were self-employed and/or worked at home), it also reflects the situation of women in the job market, whose rights are often not respected. ${ }^{18}$

The average duration of exclusive breastfeeding among the mothers who were able to go on maternity leave was 3.8 months. As the period ensured by law is four months, this result demonstrates the importance of this right for the maintenance of exclusive breastfeeding. ${ }^{19}$ Considering the mothers with formal work, $21(22.6 \%)$ reported being able to reconcile breastfeeding and work by taking breaks during working hours to breastfeed or organizing times for breastfeeding in accordance with their working hours so that it was not necessary to interrupt exclusive breastfeeding.

Among the mothers who were unable maintain breastfeeding during work, 57 were registered and, among these women, 16 had to discontinue breastfeeding due to their work and six mothers reported having lost their jobs because of breastfeeding. This demonstrates that women who work outside the home and do not receive maternity leave have a threefold greater chance of discontinuing breastfeeding. ${ }^{20}$ There is a mismatch between public health and work policies, as exclusive breastfeeding is recommended for six months, whereas maternity leave is only ensured for four months, leading many women to discontinue breastfeeding, independently of their professional background. $^{21}$

However, it should be stressed working outside the home per se does not hinder exclusive breastfeeding. The decisive factor is the right to maternity leave. Not receiving this right can lead to a financial strain on the family budget. ${ }^{20}$ Thus, working is an important factor when breastfeeding, as women currently contribute directly to the family income. ${ }^{22}$

\section{Mothers who did not breastfeed}

In the present study, $24(6.2 \%)$ mothers did not breastfeed their children. The main reasons were "weak"/insufficient milk ( $\mathrm{n}=12)$, nipple pain or injury $(\mathrm{n}=10)$ and not wanting to breastfeed/fear of breastfeeding $(\mathrm{n}=6)$. "Weak"/insufficient milk was one of the main reasons for discontinuing breastfeeding in some studies. ${ }^{22,23}$ However, it has been reported that less than 5\% of women are physiologically incapable of producing enough milk or providing desirable infant growth through breastfeeding alone. ${ }^{22}$ Insufficient milk may be the justification given because it is a socially acceptable reason for discontinuing breastfeeding or may be a reflection of the negative influences of medicalization and commercialization on women's trust in their own capacity to feed their infants. ${ }^{24}$

An Australian study showed that the frequency and duration of breastfeeding sessions naturally diminishes over the first six months due to the increase in the child's efficiency in extracting milk. ${ }^{24}$ However, such changes may be interpreted as a "lack of interest" or "insufficient milk". If the issue is an erroneous interpretation on the part of the mother, education is essential, as knowledge regarding the course of lactation can contribute to calming mothers with regards to normal variations and avoid the unnecessary use of baby formulas and the premature discontinuation of breastfeeding.

\section{Duration of breastfeeding}

In the case of multiparous mothers, duration of breastfeeding in Table 3 only refers to the youngest child. A total of $75.7 \%$ of children up to six months of age were breastfeeding. Among those between six months and one year of age, $12 \%$ were still breastfeeding and $42 \%$ breastfed for six months or more. Among those aged one to two years, 3.4\% were still breastfeeding and $56.9 \%$ breastfed for six months or more. Among children more than two years of age, none was still breastfeeding and $60 \%$ breastfed for six months or more. The youngest children of six $(2.5 \%)$ of the 244 multiparous women were still breastfeeding and it was therefore not possible to stipulate the actual breastfeeding time to compare the duration with that of the older children. These results are worrisome, as approximately $25 \%$ of children less than six months of age were not breastfeeding, which can have negative impacts on healthy child development, the mother-infant bond and the reduction in the child mortality rate. ${ }^{4}$ 
Table 3. Duration of breastfeeding. São José do Rio Preto, 2018.

\begin{tabular}{lcccc}
\hline Time of breastfeeding & $\leq 6$ months & 6 to 12 months & 12 to 24 months & $>24$ months \\
\hline Still breastfeeding & 53 & 6 & 2 & 0 \\
Up to 1 week & 0 & 0 & 2 & 3 \\
Up to 1 month & 2 & 1 & 3 & 10 \\
Up to 3 months & 6 & 6 & 10 & 29 \\
Up to 6 months & 4 & 14 & 12 & 34 \\
Up to 9 months & - & 14 & 21 & 77 \\
Up to 12 months & - & 7 & 0 & 3 \\
Up to 24 months & - & - & - & 0 \\
More than 24 months & - & 2 & 2 & 15 \\
Did not breastfeed & 5 & 2 & 64 & 2 \\
Did not answer & 7 & 52 & 62 & 192 \\
\hline Total & 77 & & 6 & 2 \\
\hline
\end{tabular}

Introduction of foods, bottle feeding and pacifier One of the causes of the discontinuation of breastfeeding is the early introduction of complementary foods. Among the participants, 252 $(65.5 \%)$ reported introducing some type of food before the infant was six months of age. The most commonly used foods were formula/artificial milk $(38.1 \%)$, juices/teas $(38.1 \%)$, water $(36.1 \%)$ and cow's milk or other type of milk (18.3\%). This finding is worrisome, as the introduction of complementary feeding prior to six months of age is related to an increase in gastrointestinal diseases due to the introduction of contaminated water and foods. ${ }^{25}$ It is also important to point out that the introduction of new foods after six months is done considering breast milk to be complete nutrition. ${ }^{26}$

The use of pacifiers and baby bottles is another cause of the early discontinuation of breastfeeding. In the present study, 279 mothers $(72.5 \%)$ reported giving their children a bottle and/or pacifier and 154 $(55.2 \%)$ reported doing so before the child reached six months of age. As suckling at the breast is an undulating movement, whereas sucking the artificial nipple of a bottle is a transverse movement, the introduction of these devices exerts an influence on orofacial development, altering the musculature of the suckling apparatus, ${ }^{27,28}$ which may no longer adapt to the mother's breast, leading to the discontinuation of breastfeeding.

Based on these data, there may be an association between the high rates of nipple injuries and the early introduction of pacifiers and baby bottles. Indeed, among the mothers who gave these devices to their children prior to six months of age $(n=154), 68$

(44.2\%) reported nipple pain and injury (intensity scores of 4 and 5). This may be an indication that the change in sucking pattern leads to difficulty in terms of proper latching at the time of breastfeeding, possibly causing pain and injury. Another hypothesis would be that mothers with these signs and symptoms caused by breastfeeding offer pacifiers and bottles in an attempt calm their babies while alleviating their breasts and nipples.

\section{Positive feelings during breastfeeding}

In the analysis of positive feelings while breastfeeding, the results show the importance of this practice to the psychosocial wellbeing of mothers, as evidenced by the low rates of negative answers to all questions posed and the responses of the "sensation of being a mother", "care" and "love" (Table 4). These positive feelings are generated by wellbeing related to the act of breastfeeding in terms of the benefits that the mother knows she is providing to her baby and the self-satisfaction of the act of breastfeeding. ${ }^{29}$

Table 4. Positive feelings at time of breastfeeding ( $\mathrm{n}$ = 385). São José do Rio Preto, 2018

\begin{tabular}{lcc}
\hline Feelings & Yes & No \\
\hline pleasure & 348 & 37 \\
good sensation & 353 & 32 \\
closeness & 365 & 20 \\
love & 367 & 18 \\
emotion & 352 & 33 \\
sensation of mother & 368 & 17 \\
care & 367 & 18 \\
best experience in life & 380 & 5 \\
\hline
\end{tabular}


"Pleasure" received the greatest number of responses of "no" in Table 4 regarding positive feelings linked to breastfeeding, which may be associated to an unpleasant sensation caused directly by lactation or indirectly through unpleasant situations caused by pressure from spouses, other family members, work or financial issues. Feelings of pleasure or displeasure become confused due to the fact that they are accompanied by dilemmas related to being a woman, wife and mother. ${ }^{29}$

The lack of knowledge among the mothers regarding the advantages of breastfeeding and the possible lack of preparation on the part of health professionals for the proper counseling of these women are factors related to the situation reported in the present study. It is fundamental to reflect on the responsibility attributed to a mother regarding the survival and health of her infant through breastfeeding, considering difficulties and limits associated with the woman's subjectivity and the articulation between need-desire-demand.

It is possible to plan more effective health actions from the identification of the determinant factors regarding the discontinuation of breastfeeding according to the mothers. Without creating a safe space for women to discuss their biological, psychoemotional and socioeconomic difficulties, health professionals miss the opportunity to influence the establishment and maintenance of breastfeeding at strategic moments. Thus, broader support is needed so that these women are not only orientated, but also encouraged and heard. ${ }^{30}$

Based on the findings regarding the difficulties encountered during breastfeeding and the reasons given by the mothers who did not breastfeed, simple measures could be taken to increase adherence to and the maintenance of breastfeeding, such as counseling on the technique to avoid nipple pain and injury, which can cause suffering and premature weaning, teaching mothers to recognize signs of adequate milk supply and consumption, such as adequate weight gain and the frequency of wet diapers, and counseling mothers on changes related to the early introduction of pacifiers, baby bottles and complementary foods. Such measures are fundamental for mothers to understand breastfeeding as well as feel safer and assisted. However, besides being prepared to give technical advice related to lactation, the work of promoting and supporting breastfeeding will not be successful if the professional does not consider emotional aspects, family culture and the woman's social support network.

Regarding positive feelings associated with breastfeeding, a broader investigation of the psychoemotional effects on women is necessary, as the answers given may be a reflection of societal influences and pressures. Answering "yes" to feelings such as "the best experience in life", "love" and "the sensation of being a mother" may be related to what is socially expected. Thus, an approach is needed that facilitates the understanding of a woman's life history and enables her to bring up ambivalent feelings.

Maternal leave is one of the favorable measures for the maintenance of exclusive breastfeeding. It is necessary to respect the rights of mothers so that they can reconcile work and breastfeeding with no negative consequences, such as being fired, which was mentioned by some of the mothers in the present study. Changes such as an increase in the period of maternity leave or the flexibilization of labor laws would be important to avoiding the discontinuation of exclusive breastfeeding, which, if performed for a longer period of time, would likely result in less pacifier/bottle use and the later introduction of complementary foods.

\section{References}

1. Dovey TM, Staples PA, Gibson EL, Halford JCG. Food neophobia and 'picky/fussy' eating in children: a review. Appetite 2008;50:181-93.

2. Brasil. Ministério da Saúde. Secretaria de Atenção à Saúde. Departamento de Atenção Básica. Saúde da criança: nutrição infantil: aleitamento materno e alimentação complementar. Ministério da Saúde, Secretaria de Atenção à Saúde, Departamento de Atenção Básica. - Brasília: Editora do Ministério da Saúde, 2009.

3. Passanha A, Benicio MHD, Venâncio SI, Reis MCG. Implementation of the Brazilian Breastfeeding Network and prevalence of exclusive breastfeeding. Rev Saúde Públ 2013;47:1141-8.

4. Victora CG, Bahl R, Barros AJ, França GV, Horton S, Krasevec J, Murch S, Sankar MJ, Walker N, Rollins NC; Lancet Breastfeeding Series Group. Breastfeeding in the 21st century: epidemiology, mechanisms, and lifelong effect. Lancet 2016;387:475-90.

5. Global Breastfeeding Collective, UNICEF, World Health Organization. Nurturing the health and wealth of nations: the investment case for breastfeeding. WHO; 2017. Available from:

http://www.who.int/nutrition/publications/infantfeeding/glob al-bf-collective-investmentcase.pdf?ua $=1$. [Last accessed on 2018 Mar 12].

6. World Health Organization. The optimal duration of exclusive breastfeeding: a systematic review. Geneva: WHO; 2001.

7. Segall-Corrêa AM, Marín-León L, Panigassi G, PérezEscamilla R. Amamentação e alimentação infantil. In: Ministério da Saúde. Pesquisa Nacional de Demografia e Saúde da Criança e da Mulher - PNDS 2006. Brasília: Ministério da Saúde; 2009. p. 195-212.

8. Diogo EF, Souza T, Zocche DA. Causas do desmame precoce e suas interfaces com a condição socioeconômica e escolaridade. Enferm foco 2011;2:10-3.

9. O'brien M, Buikstra E, Hegney D. The influence of psychological factors on breastfeeding duration. J Adv Nurs 2008;63:397-408.

10. Ferrari AG, Cherer EQ, Piccinini CA. Aspectos subjetivos da amamentação e desmame: evidências em três casos. Psic Teor Pesq 2017;33:e33411.

11. Winnicott DW. (A amamentação como forma de comunicação (J. L. Camargo, Trad.). In: Os bebês e suas mães. São Paulo: Martins Fontes. 2006; p. 19-27. (Original publicado em 1968).

12. Lucas R, Bernier K, Perry M, Evans H, Ramesh D, Young E, Walsh S, Starkweather A. Promoting self-management of 
breast and nipple pain in breastfeeding women: protocol of a pilot randomized controlled trial. Res Nurs Health 2019;42:176-88.

13. Macedo MDS, Torquato IMB, Trigueiro JVS, Albuquerque AM, Pinto MB, Nogueira MF. Aleitamento materno: identificando a prática, benefícios e os fatores de risco para o desmame precoce. Rev enferm UFPE 2015;9:414-23.

14. Barbosa MB, Palma D, Domene SMA, Taddei JAAC, Lopez FA. Fatores de risco associados ao desmame precoce e ao período de desmame em lactentes matriculados em creches. Rev paul pediatr 2009;27:272-81

15. Ribeiro KV, Florentino CLV, Mariano DCA, Peres PLP, Rodrigues BMRD. A amamentação e o trabalho informal: a vivência de mães trabalhadoras. Revista Pró-UniverSUS 2017;8:3-9.

16. Sales C, Castanha A, Alessio R. Aleitamento materno: representações sociais de mães em um distrito sanitário da cidade do Recife. Arq bras psicol 2017;69:184-99.

17. Rezende MA, Sawaia BB, Padilha KG. Mãe boa amamenta ou a força da ideologia. Fam Saúde Desenv 2002;4:154-62.

18. Damião JJ. Influência escolaridade e do trabalho maternos no aleitamento materno exclusivo. Rev bras epidemiol 2008;11:442-52.

19. Vianna RPT, Rea MF, Venâncio SI, Escuder MM. A prática de amamentar entre mulheres que exercem trabalho remunerado na Paraíba, Brasil: um estudo transversal. Cad Saúde Pública 2007;23:2403-9.

20. Queluz M, Pereira M, Santos C, Leite A, Ricco R. Prevalência e determinantes do aleitamento materno exclusivo no município de Serrana, São Paulo, Brasil. Rev Esc Enf USP 2012;46:537-43.

21. Rocha del GMM, Santos MB. A importância da amamentação e seus reflexos no mercado de trabalho. Âmbito Jurídico [serial on the Internet]. 2006;IX(29). [cited 2019 Mar 27]. Available from: http://www.ambito- juridico.com.br/site/index.php?artigo_id=1146\&n_link=revis ta_artigos_leitura

22. Barros VO, Cardoso MAA, Carvalho DF, Gomes MMR, Ferraz NVA, Medeiros CCM. Maternal breastfeeding and factors associated to early weaning in infants assisted by the family health program. Nutrire Rev Soc Bras Aliment Nutr 2009;34:101-14.

23. Carvalho MJLN, Carvalho MF, Santos CR, Santos PTF. Primeira visita domiciliar puerperal: uma estratégia protetora do aleitamento materno exclusivo. Rev paul pediatr 2018;36:66-73.

24. Newby RM, Davies PS. Why do women stop breast-feeding? Results from a contemporary prospective study in a cohort of Australian women. Eur J Clin Nutr 2016;70:1428-32.

25. Campos AMS, Chaoul CO, Carmona EV, Higa R, Vale IN. Exclusive breastfeeding practices reported by mothers and the introduction of additional liquids. Rev Latino-Am Enfermagem 2015;23:283-90.

26. Gusson ACT. Hábitos alimentares de crianças com idade até 5 anos de São José do Rio Preto [thesis]. São José do Rio Preto: Faculdade de Medicina de São José do Rio Preto; 2009.

27. Batista CLC, Ribeiro VS, Nascimento MD, Rodrigues VP. Association between pacifier use and bottle-feeding and unfavorable behaviors during breastfeeding. J Pediatr (Rio J) 2018;94:596-601.

28. Sánchez-Molins M, Grau Carbó J, Lischeid Gaig C, Ustrell Torrent J. Comparative study of the craniofacial growth depending on the type of lactation received. Eur J Paediatr Dent 2010;11:87-92.

29. Marques DM, Pereira AL. Amamentar: sempre benefícios, nem sempre prazer. Cienc Cuid Saúde 2010;9: 214-9.

30. Peixoto LO, Azevedo DV, Britto LF, Vasconcelos IN. "Breast milk is important": what do nursing mothers in Fortaleza think about breastfeeding? Rev Bras Saude Mater Infant 2019;19:157-64 